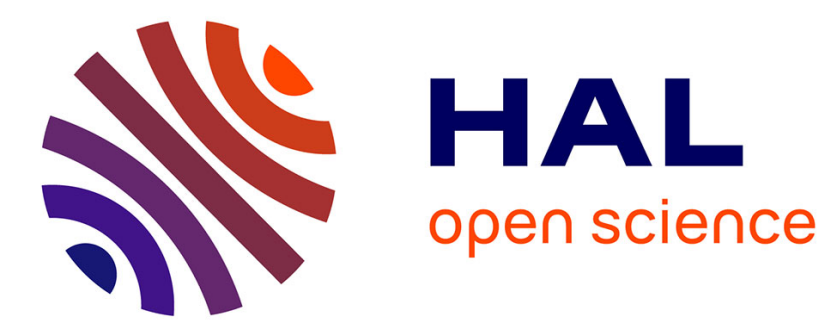

\title{
Modelling interactions to support and manage collaborative decision-making processes in design situations.
}

Eric Bonjour, Farouk Belkadi, Nadège Troussier, Maryvonne Dulmet

\section{- To cite this version:}

Eric Bonjour, Farouk Belkadi, Nadège Troussier, Maryvonne Dulmet. Modelling interactions to support and manage collaborative decision-making processes in design situations.. International Journal of Computer Applications in Technology, 2009, 36 (3-4), pp.259-271. 10.1504/IJCAT.2009.0280048 . hal-00433905

\section{HAL Id: hal-00433905 \\ https://hal.science/hal-00433905}

Submitted on 20 Nov 2009

HAL is a multi-disciplinary open access archive for the deposit and dissemination of scientific research documents, whether they are published or not. The documents may come from teaching and research institutions in France or abroad, or from public or private research centers.
L'archive ouverte pluridisciplinaire HAL, est destinée au dépôt et à la diffusion de documents scientifiques de niveau recherche, publiés ou non, émanant des établissements d'enseignement et de recherche français ou étrangers, des laboratoires publics ou privés. 


\title{
Modelling interactions to support and manage collaborative decision- making processes in design situations
}

\author{
Eric Bonjour* \\ FEMTO-ST Institute - UMR CNRS 6174, ENSMM, UFC, UTBM \\ Automatic Control and Micro-Mechatronic Systems Department \\ 24, rue Alain Savary, 25000 Besançon, France \\ Phone: +33 (0)3 81402798 \\ Email: ebonjour@ens2m.fr \\ ${ }^{*}$ Corresponding author
}

\author{
Farouk Belkadi, Nadège Troussier \\ Université de Technologie de Compiègne \\ Département GSM, CNRS UMR6253 Roberval, \\ Centre Pierre Guillaumat, BP 60319, \\ Rue du Docteur Schweitzer, 60203 Compiègne, France \\ Phone : +33(0)3 44234423 \\ Email: fbelkadi@utc.fr \\ Email: nadege.troussier@utc.fr
}

\section{Maryvonne Dulmet}

FEMTO-ST Institute - UMR CNRS 6174, ENSMM, UFC, UTBM

Automatic Control and Micro-Mechatronic Systems Department

24, rue Alain Savary, 25000 Besançon, France

Phone: +33 (0)381402791

Email: $\underline{\text { mdulmet@ens2m.fr }}$

\begin{abstract}
To cope with the increasing complexity of products, New Product Development (NPD) projects require the involvement of several designers coming from various functional departments. Designers' decisions imply modifications on different objects and are likely to affect the decision-making of other designers. Two kinds of collaborative activities are strongly inter-related: technical ones that result in decisions regarding the product definition and organizational ones that concern the project organization. In this paper, we aim at developing a new conceptual framework for modelling, managing and tracking decision-making processes that are knowledge-intensive and collaborative. This framework intends to help designers to support both technical and organizational decisions. Its originality comes from the concepts of "specific role" and "action plan" that enhance the recursive modelling of activities and are valuable at different detail levels of the decisionmaking processes: project, team and individual levels. Specific decision-making models and an industrial case study illustrate the relevance of the proposed framework.
\end{abstract}

Keywords: Collaborative design, collaborative decision-making process, knowledge and information management, interaction modelling.

Reference to this paper should be made as follows: Bonjour, E., Belkadi, F., Troussier N. and Dulmet M. (2008) 'Modelling interactions to support and manage collaborative decision-making processes in design situations', Int. J. Computer Applications in Technology, Vol. ?, Nos. ??, pp.?-?. 


\section{INTRODUCTION}

A NPD project is a multidisciplinary collaborative process in which the designers deal with the same complex product (or its interrelated components) with different views (Liang and Guodong, 2006) and eventually with different goals. Collaboration is an efficient way to share useful knowledge between actors in aims to improve the collaborative decision-making inside the project team (Kvana and Candyb, 2000). Collaboration is necessary to solve different conflicts that are direct consequences of the strong interdependencies between the actors' activities and decisions (Klein and al., 2003).

The needs of collaboration among designers do not aim at solving technical problems only (technical aspect) but rather at building or adapting the project organization (organizational aspect) (Chiu, 2002 ; Coates and al. 2004). Numerous research works dealing with design collaboration issues mainly aim at providing designers with a Computer Supported Collaborative Work (CSCW) tool to help them to solve technical points of product design (Guareis de Farias and al., 2000 ; Liang and Guodong, 2006 ; Gonnet and al., 2007). In the context of concurrent engineering, Prasad (1996) identified coordination as an element of cooperative teams within concurrent engineering organizations.

In project management, three management levels are usually identified: the project level, the team level and the member level. While the project is globally structured by its processes and their decomposition, the teams' activities and the members' activities are not completely structured at the beginning of the project. At the team and member levels, the activities are assigned according to the actors' competencies (Fitzpatrick and Askin, 2005).

DSM tools may be used in a top-down approach in order to optimize tasks sequencing, to structure project teams (Eppinger and al. 1994 ; Chen and Lin 2003) or to visualize shared modules in product models (Agrawal and al. 2004).

Collaborative activities are based on action plans that have been progressively built (in a bottomup approach) whereas the other actors define mutual requirements according to their local solutions and their own action plans. The technical solution and the project organization emerge from a collaborative decision-making process with different consensus or trade-off, unforeseeable at the beginning of the project because of different reasons:

- The context of the design project (market, technology, suppliers...) creates different sources of uncertainty that result in needs for project organization modifications because previous decisions were based on erroneous assumptions.

- The goals (or corresponding prescriptions) are not completely defined at the beginning of the project. They evolve at the same time as the solution is under development.

- The solution is only satisfactory but not optimum. The designer has to make choice among acceptable solutions according to performance criteria (multiple criteria decision-making). There is no completely defined method (or algorithm) to find this solution.

- The product parameters and their relationships are allocated to interdependent sub-systems. Their design requires emergent collaborative decisions like problem solving or conflict management.

- The decision-making process during these exchanges affects both the results concerning the product definition and the project organization.

- Finally, the integration and evaluation of the solution are progressively performed at the three levels (bottomup approach).

These different needs of the collaborative design, as well as at the project level (interactions and collaborative decisions between teams), at the team level (interactions and collaborative decisions between members) or at the member level (individual activities), require a conceptual framework helping to represent, with integrated models, the collaborative decision-making processes and the interactions among different entities of the design project. Most collaborative tools fail to support the creation and management of these multi-levels collaborative processes that are partially pre-determined or emerging.

Since researchers have paid much attention on product models (Zha and Du, 2006), we propose the formalization of the concept of design situation in aims to improve collaborative decision-making processes in two directions: to favour knowledge sharing among actors in a collaborative knowledge-intensive context and to build a shared representation of the project organization at different management levels.

First, we present an overview of the goals, tools and forms related to collaborative design. Second, we develop a conceptual framework for modelling interactions and decision-making processes with UML diagrams (Unified Modelling Language). We represent different forms of collaboration process to illustrate the interests of the proposed framework. Third, we present an industrial case study concerning a furniture design project. It illustrates the main concepts and proves that they are relevant to support and track collaborative decision-making processes.

\section{LITERATURE SURVEY}

Many collaborative systems, such as CSCW or PLM (Product Lifecycle Management), have been proposed with the purpose of assisting actors in their collaborative design activities (Shen and al. 2006; Boujut and Laureillard 2002 ; Sriram 2002). The development of new information technologies (such as web-based and agent-based applications) enhances the development of collaborative Decision Support Systems and Knowledge-Based System (Pahng and al., 1998 ; Shen and Wang, 2003 ; Linfu and Weizhi, 2005 ; Zha and Du, 2006), specially in the case of geographically distributed project activities (Agrawal and al., 2004 ; Eynard and al., 2005 ; Cao and al., 2005). 
Collaborative DSS have to integrate the following features of decision-making processes in design projects: multicriteria multi-perspectives design problem (Huang 2002 ; Agrawal and al., 2004 ; Chim and al. 2004, Cil and al. 2005), knowledge-intensive distributed product modelling (Zha and Du, 2006 ; Barthès and Tacla 2002 ; GzaraYesilbas and al. 2006), conflict-oriented problem solving (Lu and al. 2000 ; Ouertani and al. 2006).

\subsection{Collaboration goal}

Different goals for collaboration in design projects can be specified, as follows:

- to gather all knowledge related to the design process and the desired product and to share it between the actors of the project. Collaboration aims at providing a common language for all concerned actors and facilitating the acquisition of knowledge (Kvana and al., 2000 ; Nabuco and al., 2004) ;

- to obtain an efficient organization of the project (Chiu, 2002 ; Gonnet and al., 2007). Collaborative activities increase the consistency of individual activities performed by team members. They avoid or resolve possible conflicts concerning inconsistent results (Girard and Robin, 2006);

- to synchronize project decisions and foresee their mutual impacts. In this case, collaboration tasks help team members to react to different events resulting from other team members' decisions or those coming from external sources.

\subsection{Collaboration forms}

Simultaneously to the individual activities, several collaborative interactions are developed to insure coherence between the different actors' decisions. For example, in order to solve a technical problem, actors participate in a negotiation process that is more complex than a simple sharing of information. An actor can play different communication roles during collaboration in a design situation regarding different forms of organization (Sonnenwald, 1996). Three kinds of interaction in a workgroup are usually distinguished (Nabuco and al. 2004 ; Lahti and al. 2004): communication and cooperation and coordination.

\subsubsection{Communication}

This is the simplest form of interaction between actors without the need of a common goal. Communication is only a message transmission process, requiring both a sender and a receiver.

The communication goals may be, for instance, the need for technical help and for an expert's opinion. Communication helps the actor to construct his/her decision but its goal is not a decision-making.

\subsubsection{Cooperation}

Cooperation is a more complex mechanism than communication and uses communication as a means. While communication can be established between actors, with or without the same goals, the cooperation process involves actors sharing a common goal. The final aim of this interaction is clearly identified, that is, a collaborative decision-making process. The dependence level between participants gives information about the required type of cooperation. Two major cooperation processes are usually distinguished in collaborative design: cooperation by information exchanges and cooperation by negotiation.

\section{Cooperation by information exchanges}

Each participant informs other cooperative actors about the evolving changes in his/her activity that can affect their decisions (or the results of their activities). Relevant information has to be gathered, and shared only between concerned actors. The aim is to guarantee consistency between the interdependent results and eventually to avoid future conflicts between dependent decisions at the earliest possible moment.

\section{Cooperation by negotiation}

This kind of cooperation is carried out in the case of conflict between dependent decisions. We distinguish between two cases. In the former case, actors share the same individual goal and make collaborative decisions for the resolving of the current problem. The latter case is more complex: actors share the same global goal (conflict solving, Klein and al., 2003 ; Gzara-Yesilbas and al. 2006) but their individual goals are different regarding their activities and each one is trying to conserve the results of his decisions to his best advantage. An external trade-off may be required to resolve the conflict.

\subsection{Coordination}

Coordination requires that rules for functioning be established between the various actors. It controls the cooperation process. Control mechanisms have to do with the temporal scheduling of actions and the synchronization of individual decision-making processes (Coates and al., 2004).

\section{COLLABORATION FOR DECISION-MAKING}

Decision-making can be considered as a cognitive process leading to the selection of specific actions among several alternatives. Every decision-making implies a final choice (Reason, 1990).

In scientific literature, three decision levels have been distinguished according to their temporal impacts (from short to long term): operational, tactical and strategic. However, every decision has to be associated with human 
activity, which represents the operational context of this decision.

The outcome of decision-making generally impacts the object of the concerned activity. Another classification may be observed in NPD projects, according to the nature of this object:

- Technical decisions impact the product definition, like the choice of the best parameters, etc.

- Managerial decisions impact the organization of the project, for example: mission assignment, etc.

In addition, various situations of decision-making may be observed during the activity realization. These situations might require one of the previous collaboration forms to help the decision-maker to perform his/her activity. We distinguish between three decision-making situations in NPD projects:

- Individual decisions: the decision-maker has to perform an individual activity without any dependence on its results and the results of other activities. He/she may perform communication interactions in order to receive more information about the context or to ask for an opinion.

- Collective decisions in a cooperative context: the decision-makers have to share their viewpoint and knowledge, and to combine their capacities in order to resolve a complex problem. Their aim is to make decisions that are consistent and globally satisfactory when they all take part together in the problem solving. In order to do this, decision-makers have to be involved in interactions concerning cooperation by information exchanges.

- Decisions in conflict contexts: the decision-makers have to interact in order to resolve conflicts when their individual results are not compatible. The aim is to manage dependencies and contradictions resulting from individual decisions by using the cooperation by negotiation mechanism.

\begin{tabular}{|c|c|c|c|}
\hline & $\begin{array}{l}\text { Individual } \\
\text { decisions }\end{array}$ & $\begin{array}{l}\text { Collective } \\
\text { decisions }\end{array}$ & $\begin{array}{c}\text { Decisions in } \\
\text { conflict }\end{array}$ \\
\hline $\begin{array}{l}\text { Communi- } \\
\text { cation }\end{array}$ & $\begin{array}{c}\text { Information } \\
\text { sharing and asks } \\
\text { for opinion }\end{array}$ & & \\
\hline $\begin{array}{l}\text { Cooperation } \\
\text { by exchanges }\end{array}$ & & $\begin{array}{c}\text { Knowledge } \\
\text { sharing }\end{array}$ & \\
\hline $\begin{array}{l}\text { Cooperation } \\
\text { by negotiation }\end{array}$ & & & $\begin{array}{c}\text { Contradiction } \\
\text { resolving }\end{array}$ \\
\hline
\end{tabular}

Table 1. The relation between collaboration forms and decision-making situations

Table 1 synthesizes the relationships between generic collaboration forms discussed in the part "literature survey" and the situations of decision-making proposed above. The different cases inform about the goal of each collaboration form in the concerned decision-making situation. Note that coordination is considered as a transversal form that may be required in each decision-making situation in order to control the cooperation process with synchronization rules and an action plan.

The purpose of our work is to propose a conceptual modelling framework that helps to represent different interactions in the decision-making process and the corresponding situation.

\section{CONCEPTUAL FRAMEWORK TO SUPPORT DECISION-MAKING PROCESSES IN COLLABORATIVE DESIGN}

In this section, we present a conceptual framework for modelling the collaborative decision-making processes in design situations. This framework is based on the concepts of "situation" and "specific role". In section 5, we will propose models of collaborative decision-making processes that are based on this conceptual framework in order to illustrate its relevance for the development of collaboration tools.

In design projects, collaborative decision-making can be observed as a multi-interaction situation. Each interaction is considered as a particular form of organization that is constructed by a set of participants. According to the theories of organization, a generic structure of these interactions can be defined relating to the major categories of contributions (or roles) (Rosemann and Zur Muehlen, 1998). In design situations, some relationships may be formally established; for instance, there may be a team leader appointed by a higher authority (like a steering committee) within the organization, there may be particular job relationship (Cross and Cross, 1995).

We propose to describe the collaborative decision-making process as an interactional framework in which different users (human resources) are represented as a basic entity. These entities participate with other basic entities (product, material resources and project organization supports) in a set of interactions that may be operational interactions or collaborative interactions (communication, cooperation ...). The main point here is that in order to achieve his mission and make appropriate decisions, each actor may need more information about his activity situation and those of the collaborators concerned. Collaborative tools must help information exchanges and knowledge sharing about the designed product but also about the current project organization and the progress of current activities.

\subsection{Concept of "situation"}

The concept of situation has been discussed in several works (Houssin and al., 2006; Belkadi and al., 2006). These works have presented the characteristics of this concept and how to integrate them in order to analyze human action and the contribution made by each team member to any interaction.

We defined the concept of work situation as follows: "situation is a set of various entities and of various interactions globally describing the external environment in 
which an actor mobilizes his competencies and makes decisions". We distinguish between two kinds of entity:

- Basic entities (BE) that include all the human resources (HR) and the material resources (MR) such as product models, management tools, and communication tools.

- Interactional Entities (IE) that refer to links between the entities. Three kinds are considered: operational interactions (e.g. task, project), transactional (or collaborative) interactions (e.g. communication, cooperation, coordination) and community interactions (e.g. departments, project teams).

In our approach, the generic model of situation is described in the UML class diagram (Booch and al., 1999) by a set of entities and roles (Figure 1). Any object of the entity class can be related to another object of the interactional entity class according to a specific role, which is described as an instance object of the class "role".

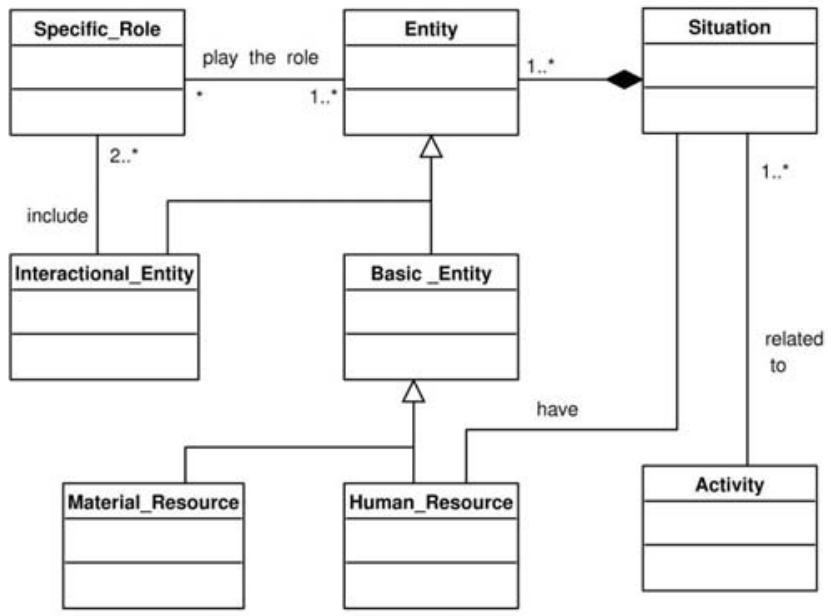

Figure 1. Generic model of situation

\subsection{Concept of "specific role"}

The concept of "specific role" (SR) is at the centre of modelling interaction. It refers to a set of specific behaviours (Uschold and al., 1998) in order to represent an actor's interpretation concerning the collaborative situation and different types of decision-making. This concept gives an organizational view regarding the contribution of each actor in the collaborative process.

We distinguish between five kinds of specific roles. With UML, we model this concept as a generic class with five sub-classes as follows:

- The "actor" role answers the question "who does what?" It concerns every entity who/which participates directly in the interaction and is responsible for the results.

- The "customer" role answers the question "For whom?" It concerns every entity who/which needs the interaction results and expresses requirements.

- The "manager" role answers the question "How?" It concerns every entity who/which regulates the functioning of an interaction and validates the final decision.

- The "support" role answers the question "With what?" It includes every entity who/which indirectly participates in the interaction or assists in its realization by sharing their knowledge or exchanging information.

- The "object" role answers the question "About what?" It concerns every entity on whom/which the interaction acts.

This formulation can make it easier to focus on different aspects of the situation model and can be used to generate useful points of view. We propose to model a collaborative decision-making process as a set of interactions among different entities who/which play different roles in each interaction. A person may play different roles in different collaborative decision-making processes.

\subsection{Concept of "mission"}

An important aspect of decision-making is the evaluation stage. A decision-maker has to select a solution among different alternatives in order to cope with a particular problem. He evaluates advantages and drawbacks of each alternative according to the evaluation criteria. After the decision-making, he has to evaluate the result of his action in order to compare the planned effects and the actual ones.

The mission view (Figure 2) helps the decision-maker to integrate different information about the context of decision-making and relevant evaluation criteria. It contains a task (considered as an operational IE), that contributes to a set of goals. The task is linked to different entities:

- The expected object and possible supports.

- Human resources and constraints that play the role of manager.

- Other contextual elements which are important to define the mission more properly ("task_framework").

- The subsequent task in the corresponding process. This task plays the role of customer.

The goals are described by different criteria. Each decision will be made according to these criteria.

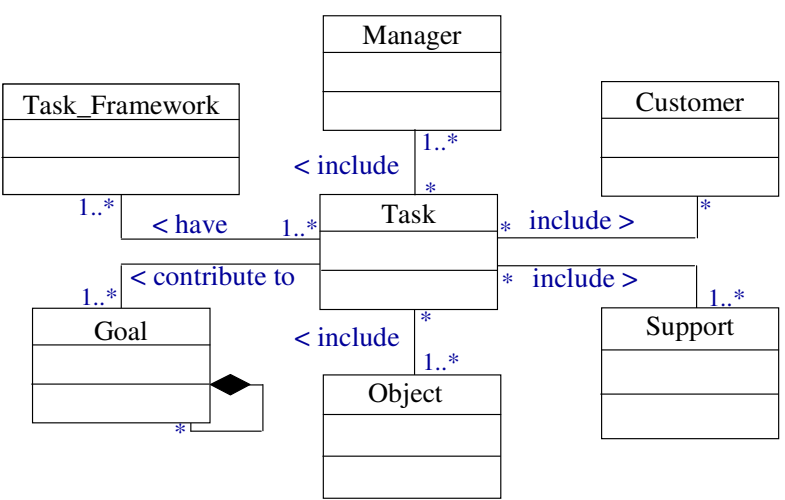

Figure 2. The mission view 


\subsection{Concepts of "activity", "action plan" and "decision- making process"}

Activity is of an operational nature. It is defined as a set of physical actions and mental decisions, by which the actor implements all material and informational resources he (she) has to deal with in the current situation. He (she) has to face this situation in order to fulfil the mission that has been entrusted to him (her). The view of activity realization associated with the carrying out of the mission includes the entities of object and manager, and in addition:

- The actor, who is either a human resource or a community IE (e.g. a department, a project team).

- The intermediate goals or results that are expected to be either produced or reached.

- Additional support (that is, material or informational resources).

Figure 3 shows that each task is carried out by an activity according to an action plan. At the beginning, the cognitive actor defines his action plan, completely or partially. The action plan contains a set of sequential actions (or partially sequential).

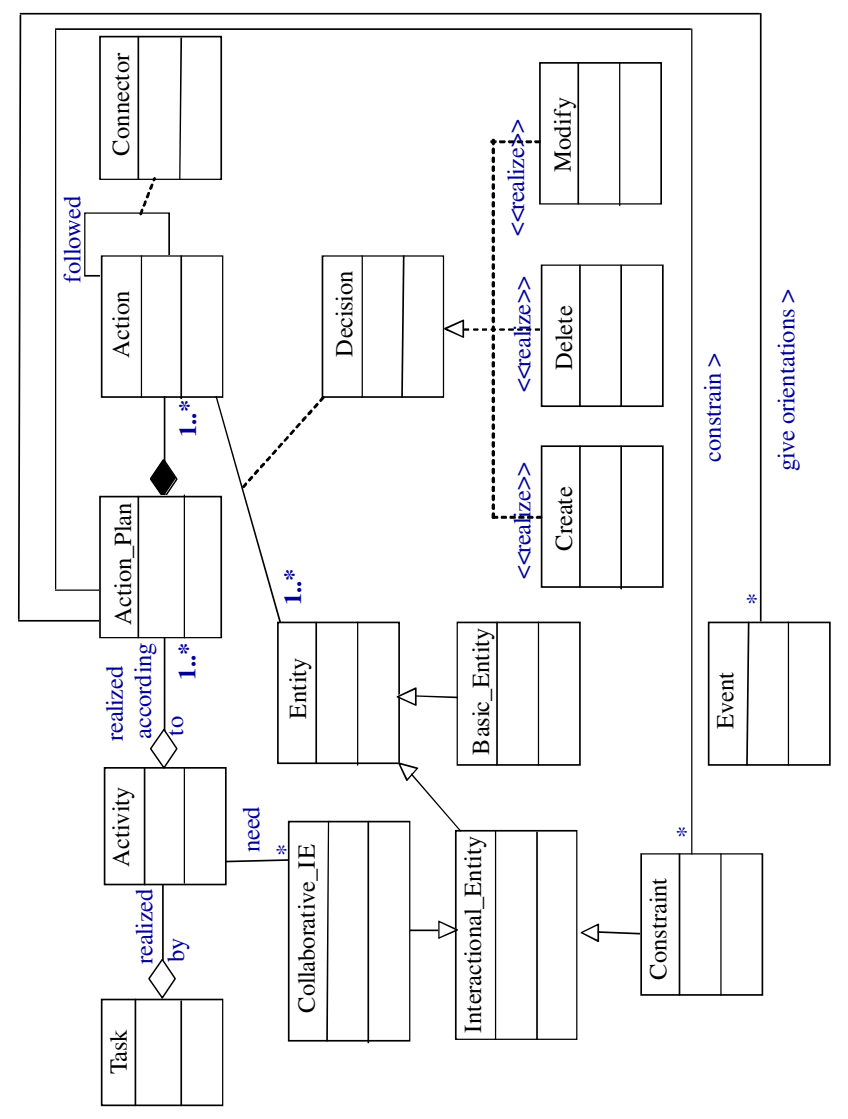

Figure 3. The model of the activity realization

The result of each action is associated to a decision that will be the creation, the deletion or the modification of one or more entities in the situation. During the activity, several modifications may be observed in the action plan (each modification is recorded in a new release). These modifications are required either by new events not envisaged at the beginning, or by the presence of new constraints generated by the activity in question or by the activities of other cognitive actors (their decision-making).

The action plan gives a representation of the cognitive organization of the activity, that is, a representation of the decision-making process. It is a description of the manner in which the actor expects to reach the task goals. Each activity may need the occurrence of one or more transactional entity in order to either validate the results (final decision-making) or solve conflict between interrelated multi-criteria decisions.

We intend to prove that this model is relevant to support and track the knowledge-intensive collaborative decisionmaking processes.

\subsection{Relationships between managerial decisions and technical decisions}

Figure 4 represents an instance of the generic model of situation corresponding to the generic decision-making process among different stakeholders. It points out interdependencies between decision-makers. In this model, each activity is associated with a particular entity according to its contribution to the task goals, that is, its specific role.

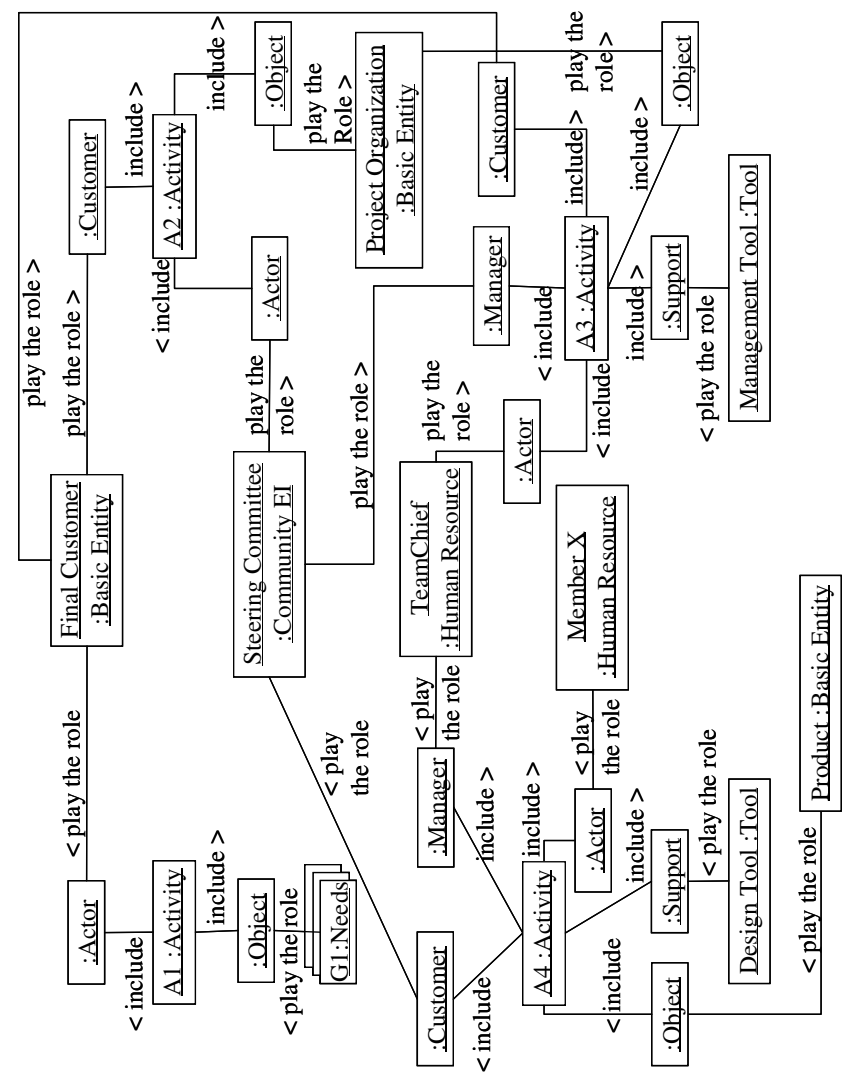

Figure 4. Instance of the situation model for the relationships between project organization and product design

In design projects, the final customer is the actor who defines the needs of the project (Activity A1), gets its final results and validates them. The steering committee makes articulation between the final customer and the other project 
actors. This committee gives more specifications about the project goals and constraints (Activity A2), defines the project team, decomposes the project into phases, plans reviews (kick-off meeting, milestones), assigns the project mission to the team chief (or leader) and validates the results at the end of the project.

According to the mission goals, the team chief (also called project manager) studies the mission feasibility, negotiates the goals and the means, describes the "project organization" in more details (Activity A3) by means of "management tool", assigns sub-missions to different team members, and validates each sub-result and their integration. The "project organization" is the object of the activities A2 and A3. Collaboration forms may be required to exchange information between the steering committee and the manager, or to negotiate the "project organization".

The team member may be in turn either a designer who defines, realizes and integrates the product structure (Activity A4) or a new sub-team in which the chief and members realize the same generic activities than the abovementioned ones... The team chief plays the role of actor regarding the Activity A3 and at the same time, he plays the role of "manager" for the team members' activities (such as Activity A4) since he assigns missions and regulates these activities. At different levels, collaborative decision-making processes evolving different project actors are often necessary to find both an appropriate project organization and a satisfactory product definition.

\section{MODELS OF COLLABORATIVE DECISION-MAKING PROCESSES}

The description of a decision-making process is obtained according to the properties of specific roles and their behaviours during the interactions. In this section, UML activity diagrams are used to model the dynamic aspect of each decision-making process. We propose three diagrams concerning task achievement, cooperation by information exchanges and cooperation by negotiation.

\subsection{Task achievement}

The major interest of the role concept is that it makes it easier to obtain a generic representation of the progress of every decision-making process. The UML activity diagram (Figure 5) illustrates the case of achieving a task (or a mission). The "customer" expresses his needs through a task and creates the Interactional Entity (IE): "task". This task is assigned by a "manager". It follows that a new entity is created: "activity". And the entity that performs the task is an "actor". First, the "actor" analyses his situation and then, he defines his action plan. He may modify the structure of the plan at any moment of his activity and records the modifications throughout the progress of his activity progress. The activity performed implies a new action that concerns the creation or the modification of an entity of the situation.
The nature of this entity is defined according to the nature of the activity. It may be either a product entity concerning technical design decisions (see Fig. 4, Activity A4) or an organizational entity (e.g. tools for project structuring and management) concerning organizational decisions (see Fig. 4, Activities A2 and A3). The "manager" has access to the collaborative system. He has to observe, follow and regulate the progress of the activity. He also reports all apparent problems and gives help in solving them. At the end, the "customer" receives the final result and closes the interaction.

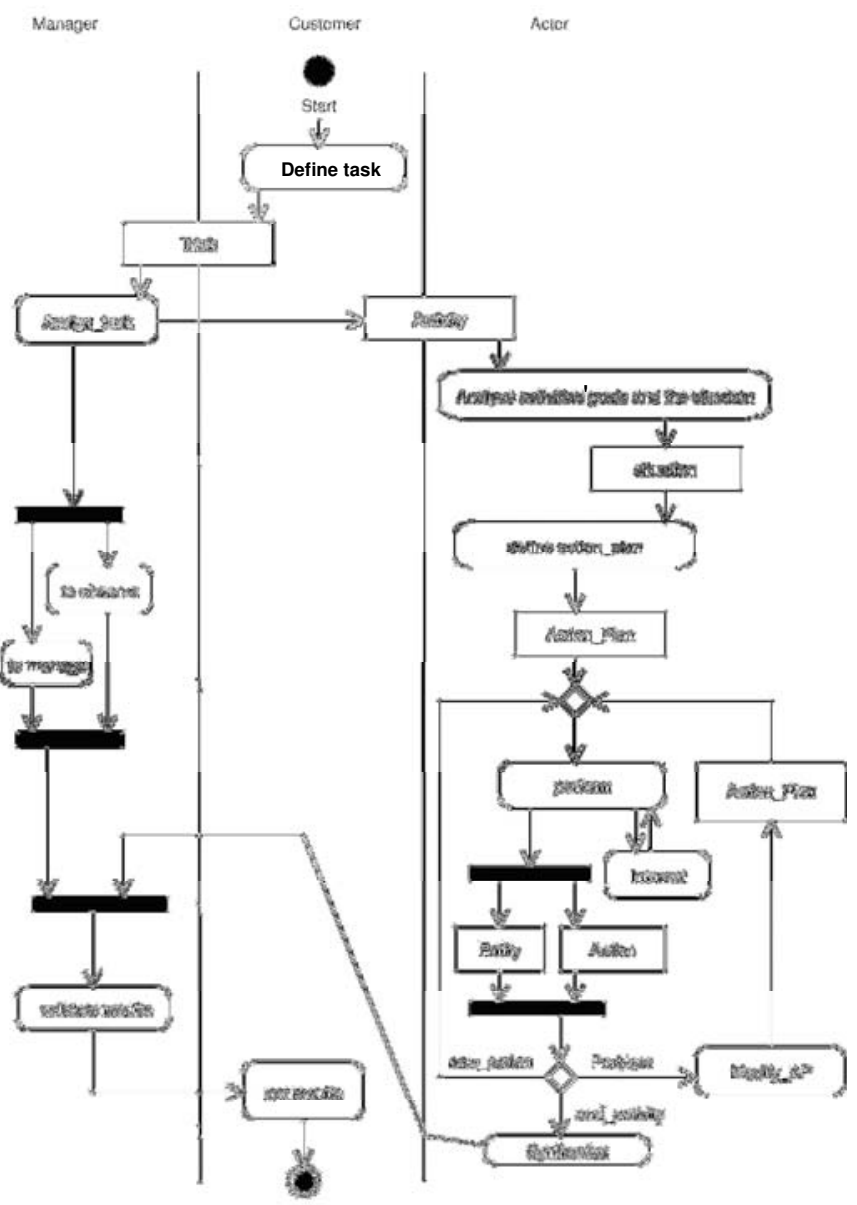

Figure 5. Decision-making process concerning the task achievement

\subsection{Cooperation by information exchanges}

The second example of using the concepts of specific roles for decision-making modelling concerns the process of cooperation by information exchanges (Figure 6). The cooperation process is similar to the communication process as it is activated by the sending of a message.

This message informs other collaborative members that a member who plays the role of "customer" needs information about other dependent activities in the project. The members of the team concerned take on the role of "actor" and share relevant information about their work situation. They send information, ask for new information and announce any problem that can be a source of conflict. At the same time, a 
"manager" role has to be defined for this interaction (it may be the project team chief or another team member without real authority in the team organization). The mission of this "manager", in this interaction, is to check coherence between all decisions. The cooperation process ends when the "manager" has confirmed that all the participants are sharing the useful information they need to make the right decisions.

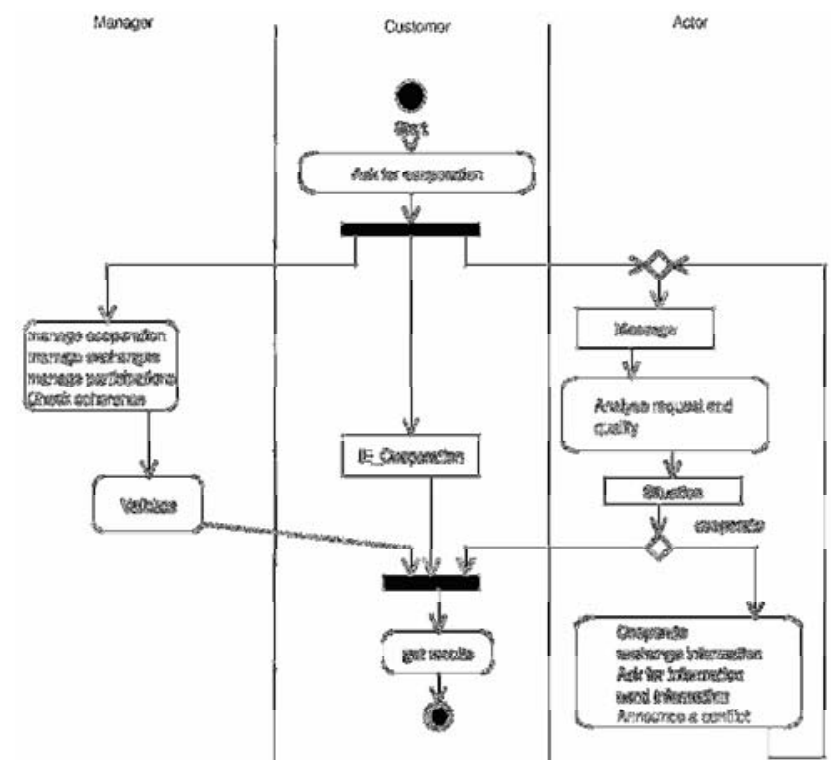

Figure 6. Decision-making process concerning cooperation by information exchanges

\subsection{Cooperation by negotiation}

The structure of the negotiation process is the same as that of cooperation for problem solving.

As shown in Figure 7, this decision-making process is composed of a set of specific messages that may be propositions, counter-propositions, validations or refusals of propositions and arguments to justify propositions and decisions. Negotiation begins whenever a team member announces a conflict problem that may have been detected during a previous cooperation exchange. It ends when the actors arrive at a satisfactory compromise that is in turn validated by the cooperation manager. If the conflict is not resolved by negotiation, cooperative actors ask for the mediation of the manager. Other authors have already modelled the conflict solving process in more detail.

\section{CASE STUDY: A FURNITURE DESIGN PROJECT}

In this case study, we monitored a design project in a big firm that manufactures furniture and distributes its products through a sales network. It allowed us to closely support and track designers' and managers' decision-making processes, specifically, in the conceptual design and the embodiment design.

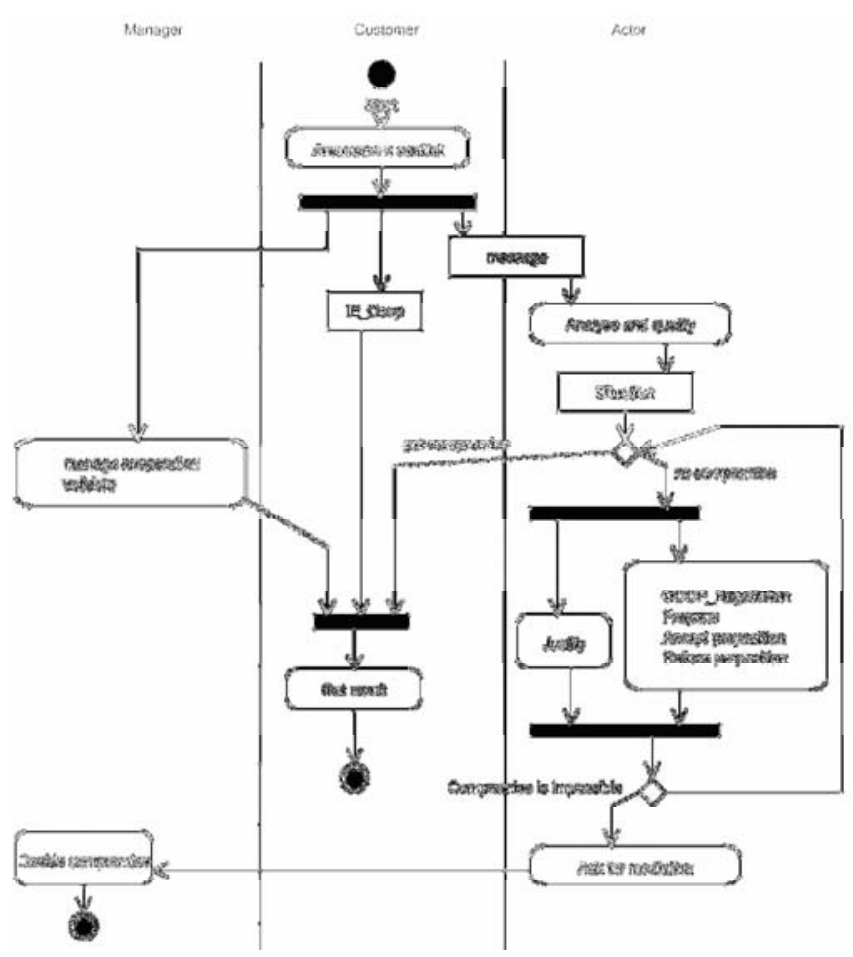

Figure 7. Decision-making process concerning cooperation by negotiation

\subsection{Brief description of the project}

The project was to design a new type of TV stand that was suitable for the new types of television (LCD and plasma screens) that offered a significant and functional added value. The design process was divided into four main tasks and so the project took place in four phases:

- Market research (analyzing what was already available and identifying the customers' requirements);

- Proposal of innovative concepts and elaboration of sketches (preliminary layouts);

- Technical design (elaboration of the construction structure and estimation of product costs);

- Preparation of production.

Each phase was monitored by a project review (justification and evaluation of decisions). The designers' proposals were accepted during the final project review. The agreed proposal then proceeded to the manufacturing phase (detailed design and preparation of production).

\subsection{Instance of the mission view: "analysing the existing TV stands"}

The object diagram in Figure 8 shows an instance of the class diagram related to a particular mission that consisted in analysing the existing TV stands. This mission took place during the market research phase whose goal was to determine both the target market and the current trend for the TV stands (with market forecasts over a 3 year period). This trend has to be correlated with the expected evolution of the TV market for flat and large screens. Specific TV 
stands could satisfy the requirements of customers who would buy these types of TV.

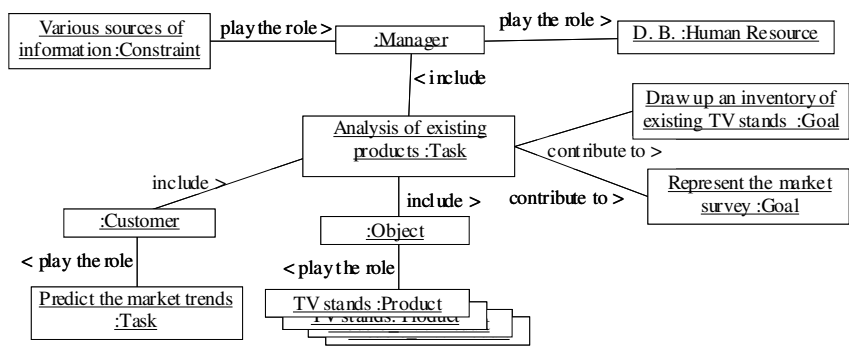

Figure 8. Instance of the mission view: "analysing the existing TV stands"

\subsection{Instance of the activity: "analysing the existing TV stands"}

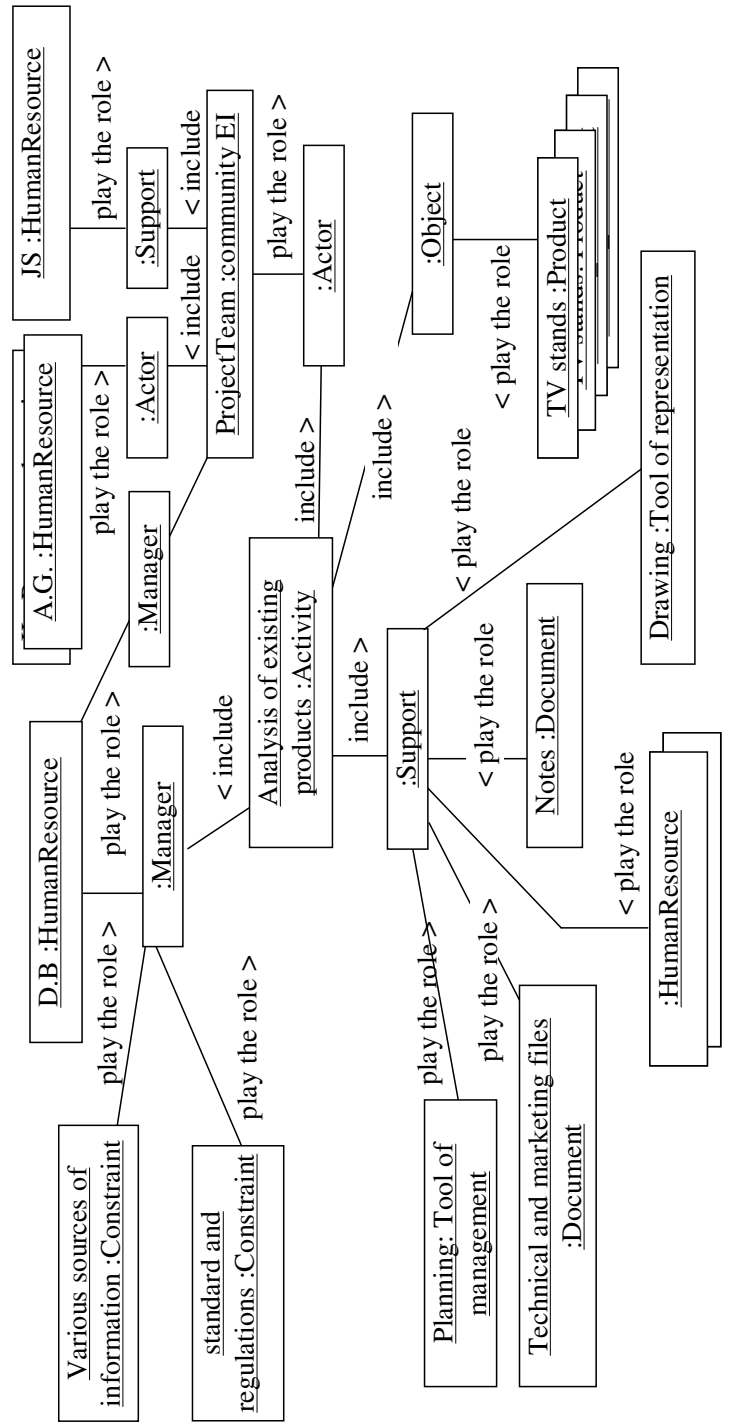

Figure 9. Instance of the activity view: "analysing the existing TV stands"

The object diagram of the associated activity is presented in Figure 9. This figure looks like Figure 8 with the difference that the activity "analysis of existing products" is linked to an "actor" role and contains more details. In this case study, the actor of this activity is a community IE which includes four human resources (two designers playing the role "actor", one "manager" and one "support").

\subsection{Instance of the activity: "elaborate CAD drawings"}

Figure 10 presents an instance of the generic model of situation relating to the activity "elaborate CAD drawings" (called Act-III.3).

According to the type of messages exchanged during this activity, we identify the role that each entity plays. The "Designer X" who transforms the object (the CAD drawing) plays the role of actor. The "Design sub_team chief" regulates the "designer X" 's activity. The former assigns a mission to the latter. He validates the results (the proposal of CAD drawing) and makes trade-off.

He plays the role of manager. The experts of the "Supplying Department" and the "Optimization Expert" give help to the designer and play the role of support. The final result of this activity is useful for the "Manufacturing Department" who has to optimize materials. The "Manufacturing Department" plays the role of customer regarding this activity. Finally, these interactions are performed by means of cooperation by information exchanges (message: "ask for ... an object" in Figure 10) and cooperation by negotiation (messages: "ask for a trade-off" and "send a decision").

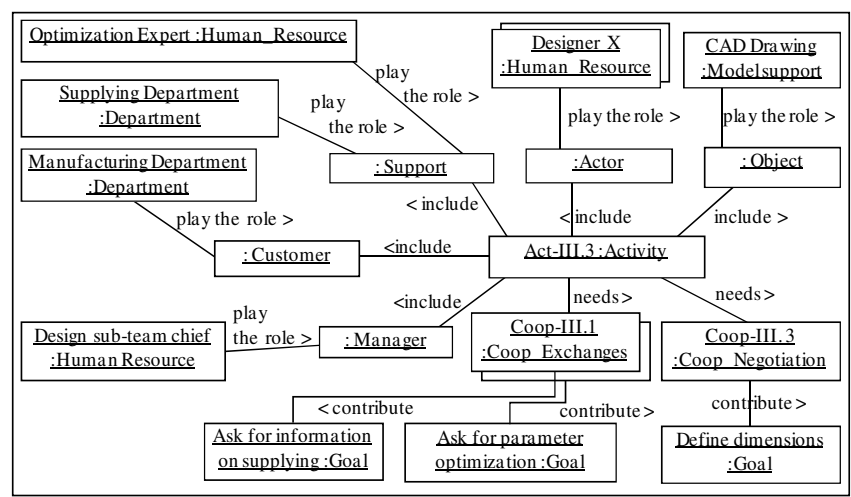

Figure 10. Instance of the situation model for the activity "elaborate CAD drawings"

\subsection{Instance of a collaborative decision-making process: "elaborate CAD drawings"}

We modelled the action plans of different activities by means of sequence diagrams.

During the "technical design" phase, several activities are performed at the team level according to a global action plan: define the construction structure (actor: Designer $\mathrm{X}$ ), check standards (actor: standards expert), elaborate CAD drawings (actor: Designer X), validate layout (actor: design sub-team chief), optimize materials (actor: Manufacturing department), elaborate definitive drawings (actor: Designer $\mathrm{X}$ ), estimate costs (actor: costing expert), validate the 
product definition (actor: design sub-team chief and project team chief).

Figure 11 represents the collaborative decision-making process concerning the activity: "elaborate CAD drawings" at the "Designer X" level. The corresponding mission was formulated as follows: develop detailed layouts and assembly solutions, and identify specific furniture accessories that need to be supplied with, in order to refine the principle solutions and the construction structure that have been checked in the former activity ("check standards").

For this activity (Act-III.3 in Figure 10), the manager is the "design sub-team chief" who assigns the mission and validates the results (i.e., the "layout"). He also gives a decision concerning the need of trade-off (for instance, "Ask for a trade-off about dimensions"). The actor is the "designer X" who performs elementary actions and asks for help to the "optimization expert" (who optimizes the furniture design parameters) and to an expert of the "Supplying Department" (who proposes the best combination of furniture hardware/accessories).

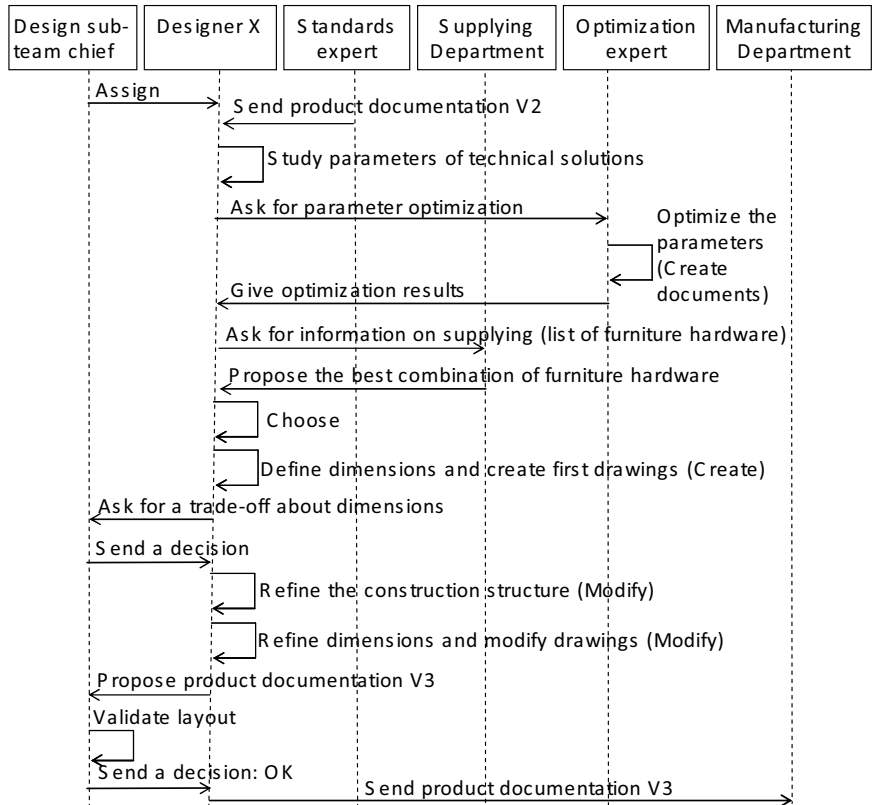

Figure 11. Scenario of the decision-making process "elaborate CAD drawings"

The analysis of this particular activity will help us to illustrate the three types of collaborative decision-making process proposed above (section 5):

\subsubsection{The task achievement}

In the previous scenario, we can identify three generic interactions involved in the model of decision-making during the task achievement (Figure 5):

- The first type concerns the interaction between the actor and the object he transforms during his/her activity. These interactions correspond to elementary actions that are associated to the decision of creation, modification or deletion of an entity, according to the model of activity (Figure 3). For instance, "define dimensions and create first drawings", "modify drawings", "optimize parameters (create documents)". These different actions are modelled in the generic decision-making process (Figure 5) as the elements of the action plan performed by the specific role "actor". In this case, the designer $\mathrm{X}$ and the experts play the role of actor.

- The second type concerns the mission assignment (message: "assign") and the validation of the result (action: "validate") at the end of the activity. During the activity, other managerial actions may be observed in order to regulate the activity, to make decisions concerning technical trade-off, Etc. This kind of action is clearly identified in the decision-making process and associated in the generic model (Figure 5) to the specific role of "manager". In the case of the task "elaborate CAD drawing", the "design sub-team Chief" plays the role of manager.

- The last type concerns the sending of the results (message: "send ..."). It could be either directly addressed by the actor to the customer or sent by the "design sub-team chief" (for instance, "send product documentation v3"). In the generic model of the decision-making (Figure 5), we associate the specific role of "customer" to the collaborator who receives the result and we present the same information with the action "get result". In the former example, the "manufacturing department" plays the role of customer for the activity "elaborate CAD drawings".

\subsubsection{Cooperation by information exchanges}

In the previous scenario (Figure 11), we can identify different types of generic messages proposed in the model of cooperation by information exchanges (Figure 6). For instance:

- The designer X starts a new cooperation when he asks for parameter optimization (called Coop-III.1 in Figure 10). Hence, he plays the role of customer for this interaction.

- The optimization expert receives the message and accepts the cooperation. He analyzes the request and qualifies his own situation by the introduction of a new mission in his planning. For this interaction (cooperation by information exchanges), he plays the role of "actor".

- The optimization expert exchanges different messages with the designer $\mathrm{X}$ in order to get more information about the product. At the end, he gives the optimization parameters as the result of this cooperation. According to this cooperation, the optimization expert gives help for the designers and plays the role of "support" in the activity "elaborate CAD drawings", (see Figure 10).

\subsubsection{Cooperation by negotiation}

Defining dimensions is an action realized by two designers. Each designer defines the dimensions of the components he 
is in charge of to design and sends this information to the other designer. The latter has to detect inconsistency with the definition of the interdependent components he is in charge of (particularly, concerning common interfaces).

In fact, this action is carried out through cooperation by negotiation between the designers (called Coop-III.3 in Figure 10). In the global process (Figure 11), the designer X is a collective actor which replaces the two designers.

Figure 12 illustrates a simple view of the negotiation process. The two designers are involved in this decisionmaking process in order to get compromise about different dimensions. According to the generic model of "cooperation by negotiation" (Figure 7), we can identify three kinds of message:

- The first message indicates the detection of a conflict. This message is sent by the designer 2 , after he receives information from the designer 1 and he detects inconsistency concerning the definition of dimensions. When the designer 2 informs his collaborator about the conflict, he creates a new "cooperation by negotiation" interaction and plays the role of "customer" for this interaction.

- The second type of messages corresponds to exchanges of propositions and responses. Following an iterative process, the designer 1 proposes modifications on the interfaces between two components. For each proposition, the designer 2 verifies if he agrees with the new parameters. The designer 1 plays the role of actor in this interaction.

- The last message occurs between the designers and the design sub-team chief. The designer 1 asks for a tradeoff concerning the conflict. The sub-team chief analyzes the actual situation and sends the final decision that is a compromise. The sub-team chief plays the specific role of manager in this interaction.

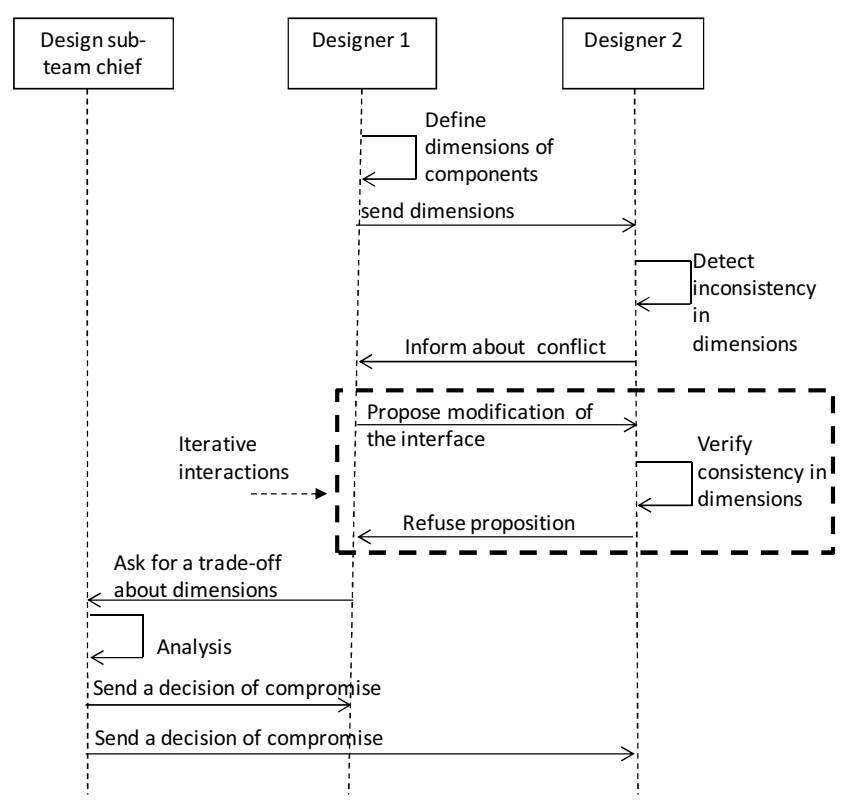

Figure 12. Example of cooperation by negotiation

\section{DISCUSSION AND CONCLUSION}

In this paper, we have proposed a modelling framework that aims to support, track and enhance the management of the decision-making processes. It intends to improve the sharing of relevant information and knowledge in collaborative design activities concerning both the product design and the project management.

The definition of generic concepts such as basic entity, interactional entity, and specific role, help represent the other concepts (mission, process ...) with a unified meaning and thus provide a high level of abstraction (specificationgeneralization links) for modelling collaborative design situations. Similarly with the concept of context in the OoactSM model (Teege, 1996), the situation class in our model is defined as a set of interrelated entities. In our models, the concept of interaction concerns all collaborative or individual activities but also different mechanisms of cooperation between members.

However, different models in the literature describe all elements existing in the context but ignore the contribution of any element in the interactions and in the decisionmaking. The concept of role is usually limited to the description of human resources' contributions in a team or a process. In our approach, the "Role" concept is explicitly identified as an independent object class. A particular interest of the "specific role" class could be expected: to obtain an original way to manage relevant displays/points of views related to the situation. The aim is to give the user access only to the relevant information with which he is concerned. When the user opens a session, the system could search for all the entities related to him in this situation. According to the user's role in any interactional entity, the system could then display the relevant level of information in his decision-making.

Finally, this modelling framework could support new collaborative Decision Support Systems permitting designers to support knowledge-intensive decision-making processes concerning both technical and organizational activities and to share information and knowledge. Stored information is also used to recognize the evolution of activities in the global process (new intermediary results, new constraints, new state of resources, etc.). The actor identifies the requirements of his partners from the present situation and the effects of their decisions on his own design situation. At the same time, every cooperative actor can obtain plenty of information about the working environment in which he interacts.

Other benefits can be obtained from this proposal: monitoring the evolution of collective work; facilitating its coordination; a better understanding of the various mechanisms which govern collaborative decision-making, and tracking causes (events, constraints) of decision-making failure or success. Further research work will present recommendations for the details required for decisionmaking process modelling in design situations. A prototype is under development and is being tested by means of an industrial case study. 


\section{REFERENCES}

Agrawal G., Parashar S., English K. W., and Bloebaum C. L. (2004) 'Web-based Visualization Framework for Decisionmaking in Multidisciplinary Design Optimization', 45th AIAA I ASME Conference, 19 - 22 April 2004, Palm Springs, California, AIAA 2004-1684

Barthès, J.P., Tacla C.A. (2002) 'Agent-supported portals and knowledge management in complex R\&D projects', Computers in Industry, 48, 3-16.

Belkadi F., Bonjour E., and Dulmet M. (2006) 'Modelling Framework of a Traceability System to Improve Knowledge Sharing and Collaborative Design', Lecture Notes in Computer Science, Springer Verlag Berlin, 3865, 355-364.

Booch, G., Rumbaugh, J. and Jacobson, I. (1999) 'The Unified Modeling Language: User Guide' USA: Addison Wesley Longman.

Boujut, J.F. and Laureillard, P., (2002) 'A co-operation framework for product-process integration in engineering design', Design Studies, 23, 497-513.

Cao J., S. Zhang, M. Li, and Wang J. (2005) 'Distributed Design Process Coordination based on a Service Event Notification model', Concurrent Engineering: Research and Applications, 13(4), 301-309.

Chen, S.J. and Lin L. (2003), 'Decomposition of interdependent task group for concurrent Engineering', Computers and Industrial Engineering, 44, 435-459.

Chim, M.Y., Anumba CJ., and Carrillo PM. (2004) 'Internet-based collaborative decisionmaking system for construction' Advances in Engineering Software 35, 357-371

Chiu M-L. (2002) 'An organizational view of design communication in design collaboration', Design Studies, 23, $187-210$.

Cil I., Alpturk O., Yazgan H. (2005) 'A new collaborative system framework based on a multiple perspective approach: InteliTeam', Decision Support Systems, 39, 619- 641.

Coates, G., Duffy, A., Whitfield, I. and Hills, W. (2004) 'Engineering management: operational design coordination', Journal of Engineering Design, 15(5), 433-446

Cross, N. and Cross, A.C. (1995) 'Observations of teamwork and social processes in design', Design Studies, 16: 145-170.

Eppinger S.., Whitney D., Smith R., Gebala D. (1994) 'A Model Based Method for Organizing Tasks in Product Development', Research in Engineering Design, 6(1), 1-13.

Eynard, B., Liénard, S., Charles, S. and Odinot, A. (2005) 'WebBased collaborative engineering support system: Application in Mechanical Design and structural Analysis', Concurrent Engineering: Research and Applications, 13(2), 145-153.

Fitzpatrick, E. and Askin, R. (2005) 'Forming effective worker teams with multi functional skill requirements', Computers and Industrial Engineering, 48, 593-608.

Girard, P. and Robin, V. (2006) 'Analysis of collaboration for project design management', Computers in industry, 57, 817826.

Gonnet, S., Henning, G. And Leone H. (2007) 'A Model for capturing and representing the engineering design process', Expert Systems with Applications, 33, 881-902.

Guareis de Farias, C.R., Pires, L.F. and Sinderen, M.V. (2000) 'A Conceptual Model for the Development of CSCW Systems', $4^{\text {th }}$ International Conference on the Design of Cooperative Systems, France.

Gzara-Yesilbas, L., Rose, B., Lombard M. (2006) 'Specification of a repository to support collaborative knowledge exchanges in IPPOP project', Computers in Industry, 57, 690-710

Houssin, R., Bernard, A., Martin, P., Ris, G. and Cherrier, F. (2006), 'Information system based on a working situation model for a new design approach in concurrent engineering', Journal of Engineering Design, 17(1), 35-54.

Huang G.Q. (2002) 'Web-based support for collaborative product design review', Computers in Industry, 48, 71-88.
James Reason (1990). Human Error. Ashgate

Klein, M., Sayama, H., Faratin P. and Bar-Yam Y. (2003) 'The Dynamics of Collaborative Design: Insights from Complex Systems and Negotiation Research', Concurrent Engineering, Research and Applications, 11(3), 201-209.

Kvana, T. and Candyb L. (2000) 'Designing collaborative environments for strategic knowledge in design', KnowledgeBased Systems, 13, 429-438.

Lahti H., Seitamaa-Hakkarainen P. and Hakkarainen K. (2004) 'Collaboration patterns in computer supported collaborative designing', Design Studies, 25 (4), 351-371.

Liang, C. and Guodong, J. 2(006) 'Product Modeling for multidisciplinary collaborative design', International Journal of Advanced Manufacturing Technology, 30, 589-600.

Linfu, S. and Weizhi, L. (2005) 'Engineering Knowledge Application in Collaborative Design', The $9^{\text {th }}$ International Conference on Computer Supported Cooperative Work in Design. (pp722-727). Coventry, UK.

Lu, S.C., Cai J., Burkett W., Udwadia F. (2000) 'A methodology for collaborative design process and conflict analysis', Annals of CIRP, 49 (1), 69-73.

Nabuco, O., Rosário, J.M., Silva, J.R and Drira, K. (2004) ' Scientific Collaboration and Knowledge Sharing in the Virtual Manufacturing Network', $11^{\text {th }}$ IFAC Symposium on INformation COntrol problems in Manufacturing, SalvadorBahia, Brazil.

Ouertani M., Gzara-Yesilbas L., and Lombard M. (2006) 'A process model based methodology to support conflict management', Information Control Problems in Manufacturing, 733-738.

Pahng F., Bae S.H., Wallace DR. (1998) 'Web-based collaborative design modeling and decision support', in: Proc. of ASME DETC'98 (CD-ROM), Atlanta, Georgia, USA.

Prasad, P. (1996) 'Concurrent engineering fundamentals: integrated product and process development', In Prentice-Hall international series in industrial and systems engineering, 2, New Jersey: Prentice-Hall.

Rosemann, M. and Zur Muehlen, M. (1998) 'Evaluation of Workflow Management Systems - a Meta Model Approach', Australian Journal of Information Systems, 6(1), 103-116.

Shen, W. and Wang, L. (2003) 'Web-Based and Agent-Based Approaches for Collaborative Product Design: an Overview', International Journal of Computer Applications in Technology, $16(2 / 3), 103-112$.

Shen, W., Chao, K.M., Lin, Z., Barthès, J-P., James, A. (2006) 'Computer Supported Cooperative Work in Design II', Lecture Notes in Computer Science 3865, Springer.

Sonnenwald, D. H. (1996) 'Communication roles that support collaboration during the design process', Design studies, 17, 277-301.

Sriram R., (2002) 'Distributed and Integrated Collaborative Engineering Design', Sarven Publishers, Glenwood, MD 21738, Decembe.

Teege, G. (1996), Object-Oriented Activity Support: a Model for Integrated CSCW Systems', Computer Supported Cooperative Work (CSCW), 5(1), 93-124.

Uschold, M., King, M., Moralee, S. and Zorgios, Y. (1998) 'The Enterprise Ontology', The Knowledge Engineering Review, M. Uschold (eds.) Putting Ontologies to Use. 13, 1-12.

Zha X., Du H. (2006) 'Knowledge-intensive collaborative design modeling and support- Part I: Review, distributed models and framework' Computers in Industry, 57, 39-55. 


\section{Biographical notes:}

Eric Bonjour is an associate professor at the University of FrancheComté (France). He has been a mechanical engineer since 1993. $\mathrm{He}$ received his $\mathrm{PhD}$ degree in Automation and Industrial Engineering in 1996. His research projects aim at developing methods and tools to assist the activities of project managers and system architects who design complex products. He is the leader of a National Research Group affiliated to CNRS concerning "the management of knowledge and competency in industrial enterprises". He has published more than 40 papers for journals (such as Computers In Industry, International Journal of Product Development, LNCS ...), conferences and books.

Farouk Belkadi is a post-doc researcher at the University of Technology of Compiegne (UTC). In 1998, he obtained his bachelor degree in automation and systems control from the Boumerdes' University (Algeria). He received his $\mathrm{PhD}$ in Automation and Industrial Engineering in 2006 at the University of Franche-Comté (associated to LAB laboratory, France). His current research interests are systems modelling, PLM approaches and computer-supported collaborative work in engineering design.

Nadège Troussier is an associate professor at the Department of Mechanical Systems Engineering, University of Technology of Compiegne (UTC). She received her $\mathrm{PhD}$ in Mechanical Engineering in 1999 at the University of Joseph Fourier, Grenoble. Her current research interests are PLM approaches and knowledge reuse in engineering design.

Maryvonne Dulmet is currently an associate professor in the department of Mecatronics at University of Franche-Comté. After obtaining a mechanical engineering degree, she received her $\mathrm{PhD}$ in the field of non linear Acoustics. She obtained her "Habilitation for leading Research" (HDR) in Production Systems Engineering in 2000. Her research interests are human factor engineering in product design and manufacturing systems. 